\title{
Research on Ignition Characteristics and Factors of Biogas Engine
}

\author{
Yanyan Wang, Xingyu Liu, Jianguo Yang, Yitao Shen and Xiangyun Feng \\ Harbin Institute of Technology at Weihai, School of Automotive Engineering, Weihai 264209, China
}

\begin{abstract}
A three-dimensional computational fluid dynamics model coupled with chemical kinetics mechanism was established and validated on an actual biogas fuelled engine. Arc and kernel tracking ignition model and coherent flame combustion model were implemented and applied to capture in-cylinder ignition and turbulent combustion. On this basis, the ignition process of biogas engine was simulated and the generation and development of flame kernel was analysed. Then the single variable method was used to study the effect of ignition system parameters, such as different ignition energy, spark plug gap and initial conditions (equivalence ratio and initial temperature) on biogas engine ignition performance. The results shows that ignition process of biogas engine can be described as three stages. Spark ignition energy has little effect on ignition performance. Increasing the spark plug gap and equivalence ratio in certain range is beneficial to igniting biogas engine. Preheating the mixture will improve the ignition performance.
\end{abstract}

Nowadays exploiting efficient and clean renewable fuel has gradually becoming a priority in development in face of global energy shortage and environmental threat ${ }^{[1]}$. Among all renewable fuel, biogas fuel has been thought highly of due to advantages of environmental protection property and renewability itself ${ }^{[2]}$. As gas fuel shares the advantage of high carbon hydrogen ratio and boasts relatively wider ignition range and better ignition ability when forming homogeneous mixed gas, which gives itself application in ignition engine ${ }^{[3]}$. Thus biomass gasified into biogas for further utilization receives considerable publicity. As known, biogas is usually utilized as living gas or directly for power generation by dissociating and gasifying biomass and then driving power equipment such as internal combustion engine or gas turbine. In this way, it could solve the combusting problem of biomass, lessen pollution and improve volume efficiency.

Early in 2003, Shudoetal in Italy and Mudtafieta ${ }^{[4]}$ in America successfully powered a small-sized ICE power generation system, which laid theoretical foundation on the possibility of making biogas the engine alternative fuel. Papagian nakisetal ${ }^{[5]}$ studied the whole engine performance and emission performance. The results revealed that the emission performance of $\mathrm{CO}$ and $\mathrm{NO}$ of biogas engine is better than that of natural gas engine. Zhangqiang $^{[6]}$ in Shandong University developed 4135 biogas engine, simulated and analyzed the model. The study demonstrated that it shared excellent emission and power performance and could facilitate fast combustion. Xiong Shusheng in Zhejiang University ${ }^{[7]}$ coupled methane with turbulence combustion chamber and found that boosting turbulence intensity, ignition energy and compress ratio could optimize the engine ignition performance.

So far, studies on biogas engine domestic and overseas mainly focus on combustion and emission characteristics analysis, meantime engine modification and parameters calibration while rarely on ignition performance. Due to this, this paper simulates ignition process of biogas engine using an engine chamber model calibrated to fit real engine test bench results. Besides, it analyzes the appearance and development process of flame kernel and the effect of parameters on ignition performance.

\section{Establishment and validation of model}

\subsection{Main parameters and computational mesh}

By reason of low thermal value and slow combustion velocity, biogas shares low power index value when it acts as the engine burning fuel. In case of this, this paper takes certain type engine of GE company as the prototype with the characteristics of large bore, low speed and long stroke. The construction and running parameters are shown in Table 1.

Traditionally, as there is no organization of flow in spark ignition engine, combustible mixed gas has no matter to do with turbulence beside the sparking plug gap. So relatively accurate simulation of this even so brief ignition process could be achieved on condition of the same initial parameters like temperature, pressure and equivalence ratio as the real engine. This paper built simplified combustion chamber model, ignoring the intake and exhaust ports model. Combustion chamber mesh at representative position is shown as Figure 1.

Table 1. Construction and running parameters of engine

\begin{tabular}{|c|c|}
\hline Name of Parameters & Value \\
\hline Type & J320GS \\
\hline Compression Ratio & 10.5 \\
\hline Combustion Chamber & Dished-head \\
\hline $\begin{array}{c}\text { Rated Power (KW) /Speed } \\
\text { (r/min) }\end{array}$ & $154 / 2800$ \\
\hline $\begin{array}{l}\text { Maximum Torque }(\mathrm{Nm}) \\
\text { /Speed }(\mathrm{r} / \mathrm{min})\end{array}$ & $6200 / 1600$ \\
\hline $\begin{array}{l}\text { Cylinder Number } \times \text { bore } \\
(\mathrm{mm}) \times \text { stroke }(\mathrm{mm})\end{array}$ & $6 \times 105 \times 120$ \\
\hline
\end{tabular}






Figure 1. Combustion chamber mesh at representative position

\subsection{Simulation method and computational model}

This paper takes biogas extracted from the Sawdust whirlwind gasification system in Combustion Engineering Research Institute of Harbin Institute of Technology. The main characteristics are shown as Table 2. While biogas contains few heavy oil and ethyne, these two components could be ignored during the simulation. Then the computation is undergone with internal compiler inside the simulation software coupled with CFD chemical kinetics model, while the chemical kinetics mechanism is $\mathrm{CH}_{4}-\mathrm{H}_{2}-\mathrm{CO}$ mixed fuel framework mechanism.

Table 2 Characteristics of biogas

\begin{tabular}{cccc}
\hline Components & $\begin{array}{c}\text { Volume } \\
\text { Percentage } \\
(\%)\end{array}$ & $\begin{array}{c}\text { Density in } \\
\text { Standard } \\
\text { condition } \\
\left(\mathrm{kg} / \mathrm{m}^{3}\right)\end{array}$ & $\begin{array}{c}\text { Low Heat } \\
\text { Value } \\
\left(\mathrm{MJ} / \mathrm{Nm}^{3}\right)\end{array}$ \\
\hline $\mathrm{CO}$ & 26 & 1.149 & 12.64 \\
$\mathrm{H}_{2}$ & 5 & 0.082 & 18.79 \\
$\mathrm{CH}_{4}$ & 4 & 0.656 & 35.88 \\
$\mathrm{CO}_{2}$ & 15 & 1.805 & - \\
$\mathrm{N}_{2}$ & 50 & 1.149 & - \\
\hline
\end{tabular}

It takes AKTIM (Arc and Kernel Tracking Ignition Mode) as ignition model which takes heat transfer and heat loss from flame kernel to unburned mixed gas region during flame kernel appearance process. In addition, this model also analyses the effect of mixed gas flow beside the sparking plug on the appearance and development of flame kernel and could simulate the influence of parameters such as ignition energy, position and plug gap on ignition process.

Considering computational efficiency and simulation accuracy, this paper takes $k-\varepsilon$ model as turbulence model and submodel ECMF of CFM (Coherent Flame Model) model as combustion model.

\subsection{Initial condition and boundary}

Biogas engines are mainly used for power generation which requires the engine speed to be the same as synchronous generator speed. The frequency of the domestic generator is $50 \mathrm{~Hz}$, and the speed options are $500,600,750,1000,1500,3000 \mathrm{r} / \mathrm{min}$ according to number of pole pairs. In view of factors such as power and rated speed comprehensively, 1500r/min was chosen as the engine working speed. Taking anchor angle as the computational and assuming the cylinder is filled with homogeneous gas mixture at the initial period, the initial value of in-cylinder pressure and temperature is computerized by one-dimension simulation software.

The boundary condition could be divided into two kinds, one with in-cylinder temperature boundary being constant everywhere in which the temperature of the top of piston, the cylinder wall and the bottom of cylinder head is set as $550 \mathrm{~K}, 450 \mathrm{~K}, 520 \mathrm{~K}$ respectively. The other one with cylinder wall and cylinder top being motionless, the velocity of the cylinder head being the same as that of the piston.

\subsection{Model validation}

To validate the accuracy of the model, the combustion characteristic at the condition of the speed being $1500 \mathrm{r} / \mathrm{min}$ and the equivalence ratio being 1 was tested in biogas engine. The tested cylinder pressure figure and simulation results are compared as shown in Table 3 and Figure 2.

Table 3 Comparison of engine simulation and experiment



Figure 2. Model validation of biogas engine

From the comparison, we can see that results of the simulation and test are in good agreement, which also agree well with the whole tendency. This reveals that the model of the paper could be applied to biogas engine combustion process simulation.

\section{Biogas engine ignition characteristic simulation analysis}

Taking crank angle as computational step, defining the top dead center as $360^{\circ} \mathrm{CA}$, the computational range being from $330^{\circ} \mathrm{CA}$ to $360^{\circ} \mathrm{CA}$, this paper simulates the ignition process of biogas engine at the condition of the engine speed being $1500 \mathrm{r} / \mathrm{min}$, the equivalence ratio being 1 , the spark advance angle being $30^{\circ} \mathrm{CA}$ and the ignition energy being $80 \mathrm{~mJ}$. 
The plot of average chemical reaction rate changing with crank angle during biogas engine ignition process in simulation condition is shown as Figure 3. From Figure 3, we could see that there are two fluctuating phenomena. The first one is because the biogas between electrodes is sparked over and the initial flame kernel is generated during sparking plug spark-over period, which leads to temporarily higher temperature, then the reaction velocity slows down and the first fluctuating phenomena appeared. The second one is because after the spark-over period, the high temperature of the ionized plasma motivate the process of chemical reaction, boosting the chemical velocity, then the ionization of the sparking plug ceased gradually which slows the chemical velocity and the second fluctuating phenomenon appeared. In this paper, the moment corresponding to peak chemical rate in the first fluctuating phenomenon is regarded as the initial flame kernel generating moment, the corresponding flame kernel radius is called initial flame kernel radius. Accordingly, the moment corresponding to peak chemical rate in the second fluctuating phenomenon is regarded as the stable flame kernel generating moment, the corresponding flame kernel radius being called stable flame kernel radius.

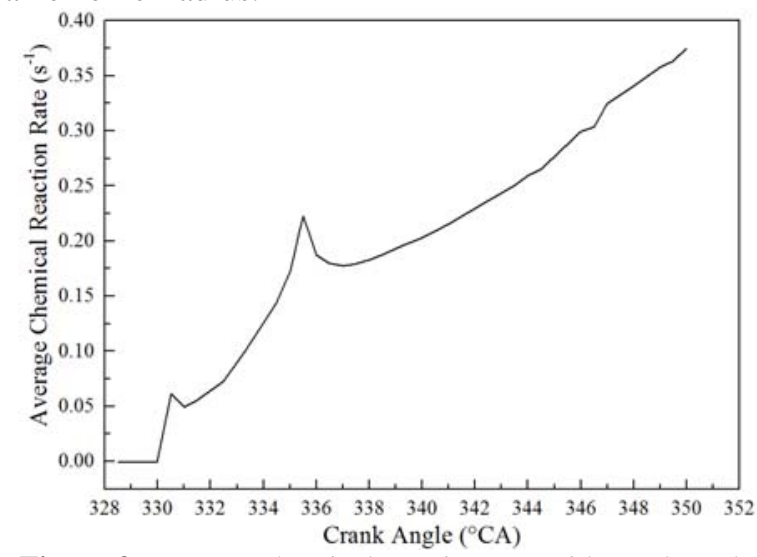

Figure 3. Average chemical reaction rate with crank angle

From Figure 3, we could draw the conclusion that after ignition, the biogas engine experienced mainly three stages. The first stage continued from ignition moment $\left(330^{\circ} \mathrm{CA}\right)$ to $330.8^{\circ} \mathrm{CA}$, during which the initial flame kernel was generated by spark-over where the influence of ignition took lead. The second stage was initial flame kernel developing stage, lasting from $330.8^{\circ}$ CA to $336.5^{\circ}$ CA, during which the stable kernel was generated and ignition process was suspended where the influence of burning heat release of the biogas itself took lead. The third stage was stable flame kernel spreading phase. In this paper, the combination of the first and second phase was called flame kernel generating period, which in simulation condition was $6^{\circ} \mathrm{CA}$.

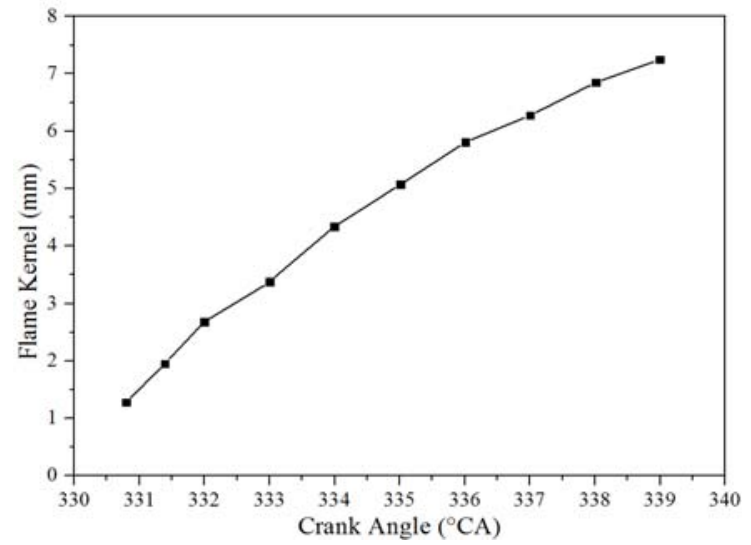

Figure 4. Flame kernel radius with crank angle

Figure 4 shows the characteristic of flame kernel radius changing with anchor angle. From Figure 4, it could be witnessed that after the generation of initial kernel, the flame kernel radius increases with anchor angle, but the velocity is getting lower. In simulation condition, the initial flame kernel radius is $1.29 \mathrm{~mm}$, and static flame kernel radius is $5.8 \mathrm{~mm}$.

\section{Influencing factors analysis of ignition for biogas engine}

The performance of spark ignition for biogas engine is mainly dominated by two kinds of factors. One is related to the ignition system, such as ignition energy and spark plug gap. The other is correlated with the characteristics of the fuel mixture, such as the equivalence ratio, initial temperature and pressure. Two different kinds of influencing factors were respectively studied in this work.

\subsection{Influence of ignition energy on ignition}

Ignition energy is defined as the energy that is generated in the breakdown of spark plug electrodes caused by high voltage. Ignition energy was changed from 10 to $160 \mathrm{~mJ}$ and the combustion was separately simulated, the results were shown in Table 4, Figure 5 and Figure 6.

Table 4 Results at different ignition energy

\begin{tabular}{ccccc}
\hline $\begin{array}{c}\text { Ignition } \\
\text { energy } \\
(\mathrm{mJ})\end{array}$ & $\begin{array}{c}\text { Flame } \\
\text { kernel } \\
\text { generation } \\
\text { duration } \\
\left({ }^{\circ} \mathrm{CA}\right)\end{array}$ & $\begin{array}{c}\text { Ignition } \\
\text { delay } \\
\text { duration } \\
\left({ }^{\circ} \mathrm{CA}\right)\end{array}$ & $\begin{array}{c}\text { Initial } \\
\text { flame } \\
\text { kernel } \\
\text { radius } \\
(\mathrm{mm})\end{array}$ & $\begin{array}{c}\text { Stable } \\
\text { flame } \\
\text { kernel } \\
\text { radius } \\
(\mathrm{mm})\end{array}$ \\
\hline 10 & - & - & - & - \\
40 & 5.8 & 16.5 & 1.06 & 5.57 \\
80 & 6 & 16 & 1.28 & 5.8 \\
120 & 6 & 16 & 1.38 & 5.89 \\
160 & 6 & 16 & 1.38 & 5.90 \\
\hline
\end{tabular}

From Figure 5, the initial flame kernel cannot be generated at $10 \mathrm{~mJ}$ and the ignition is failed. It shows that there is a minimum ignition energy to ignite biogas engine and the ignition will be failed below this level. Once ignited, the flame kernel generation duration and the ignition delay duration of biogas remain largely unchanged with the increase of ignition energy. While, 
the initial flame kernel radius displays a slightly increasing trend. Enhancing the ignition energy in certain range will improve the generation of initial flame kernel for the biogas engine. Growth rate of the flame kernel is hardly affected with the ignition energy on the flame kernel development period.

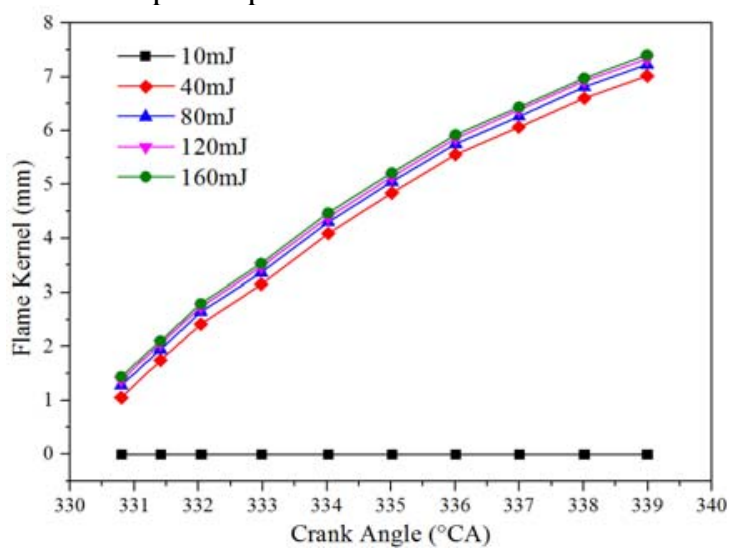

Figure 5. Flame kernel radius at different ignition energy

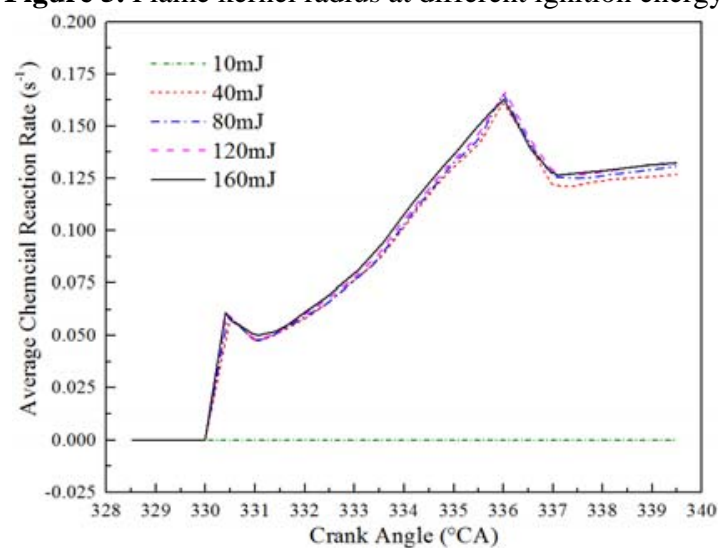

Figure 6. Chemical reaction rate at different ignition energy

Figure 6 illustrates that ignition energy make affects with the flame kernel mainly in the early stage. When the flame kernel first occurs in the combustor, the chemical reaction rate shows a bit difference which causes the distinction of the initial flame kernel. The ignition performance of biogas engine is less influenced by increasing the ignition energy separately. The stable flame kernel radius, the flame kernel generation duration and the ignition delay duration shows tiny difference at different ignition energy.

\subsection{Influence of spark plug gap on ignition}

The brake energy of spark plug for the breakdown ${ }^{[11]}$ can be defined as:

$$
E_{b d}=\frac{1}{2} C_{g a p} V_{b d}^{2}
$$

where $C_{\text {gap }}$ is the capacitance of spark plug gap (F) and $V_{b d}$ is the breakdown voltage (V).

It's known that increasing the spark plug gap will linearly improve the break energy. The spark plug gap was changed from 0.5 to $2.5 \mathrm{~mm}$ and the combustion was separately simulated, the results were shown in Table5, Figure 7 and Figure 8.
Table 5 Results at different spark plug gap

\begin{tabular}{ccccc}
\hline $\begin{array}{c}\text { Spark } \\
\text { plug gap } \\
(\mathrm{mm})\end{array}$ & $\begin{array}{c}\text { Flame } \\
\text { kernel } \\
\text { generation } \\
\text { duration } \\
\left({ }^{\circ} \mathrm{CA}\right)\end{array}$ & $\begin{array}{c}\text { Ignition } \\
\text { delay } \\
\text { duration } \\
\left({ }^{\circ} \mathrm{CA}\right)\end{array}$ & $\begin{array}{c}\text { Initial } \\
\text { flame } \\
\text { kernel } \\
\text { radius } \\
(\mathrm{mm})\end{array}$ & $\begin{array}{c}\text { Stable } \\
\text { flame } \\
\text { kernel } \\
\text { radius } \\
(\mathrm{mm})\end{array}$ \\
\hline 0.5 & - & - & - & - \\
1.0 & 6 & 16 & 1.28 & 5.8 \\
1.5 & 5 & 13.5 & 2.0 & 6.0 \\
2.0 & 7 & 17 & 2.3 & 6.0 \\
2.5 & 7.5 & 17 & 2.8 & 6.2 \\
\hline
\end{tabular}

From Figure 7, the initial flame kernel is very small and extinguishes rapidly at plug gap of $0.5 \mathrm{~mm}$, so the ignition is failed. It shows that there is a minimum spark plug gap to ignite biogas engine and the ignition will be failed below this level because of low break energy. The flame kernel generation duration and the ignition delay duration decrease obviously with the increase of spark plug gap ranging from 1.0 to $2.0 \mathrm{~mm}$. While the flame kernel generation duration and the ignition delay duration has an inverse trend when the spark plug gap is bigger than $2.0 \mathrm{~mm}$. Enlarging the spark plug gap in certain range will improve the ignition performance for the biogas engine, but excessive plug gap is harmful to biogas engine ignition.

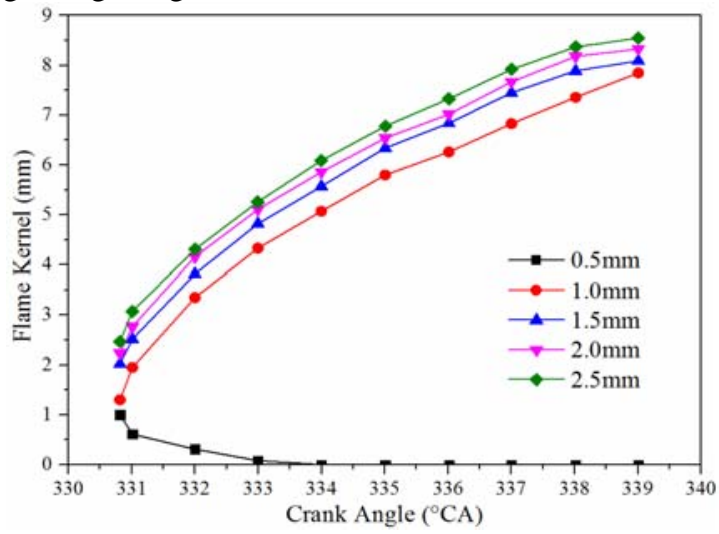

Figure 7. Flame kernel radius at different plug gap



Figure 8. Chemical reaction rate at different plug gap

As shown in the Figure 8, there is an optimal range of spark plug gap. The chemical reaction rate rises with the increase of plug gap within this range and the initial flame kernel fleetly become the stable flame kernel. The biogas engine has optimal ignition performance. 


\subsection{Influence of equivalence ratio on ignition}

The equivalence ratio is generally used to describe the concentration of biogas mixture and it can be defined as the ratio of the actual concentration and the stoichiometric concentration. The equivalence ratio was changed from 0.6 to 1.2 and the combustion was separately simulated, the results were shown in Table 6, Figure 9 and Figure 10.

Table 6 Results at different equivalence ratio

\begin{tabular}{ccccc}
\hline $\begin{array}{c}\text { Equivalence } \\
\text { ratio }\end{array}$ & $\begin{array}{c}\text { Flame } \\
\text { kernel } \\
\text { generation } \\
\text { duration } \\
\left({ }^{\circ} \mathrm{CA}\right)\end{array}$ & $\begin{array}{c}\text { Ignition } \\
\text { delay } \\
\text { duration } \\
\left({ }^{\circ} \mathrm{CA}\right)\end{array}$ & $\begin{array}{c}\text { Initial } \\
\text { flame } \\
\text { kernel } \\
\text { radius } \\
(\mathrm{mm})\end{array}$ & $\begin{array}{c}\text { Stable } \\
\text { flame } \\
\text { kernel } \\
\text { radius } \\
(\mathrm{mm})\end{array}$ \\
\hline 0.6 & - & - & - & - \\
0.8 & 8 & 21 & 0.77 & 6.88 \\
1.0 & 6 & 16 & 1.28 & 5.8 \\
1.2 & 5.5 & 14 & 1.34 & 4.55 \\
\hline
\end{tabular}

From Figure 9 and 10, the initial flame kernel is very small and extinguishes rapidly at equivalence ratio of 0.6 , so there is a minimum equivalence ratio to ignite biogas engine. The flame kernel generation duration and the ignition delay duration decrease gradually with the increase of equivalence ratio. It shows enriching the mixture in certain range is beneficial to the ignition and combustion. Meanwhile, the ignition performance is closely related with the concentration of the mixture in low level. So it's more beneficial to the ignition by enriching the mixture in low concentration combustion.

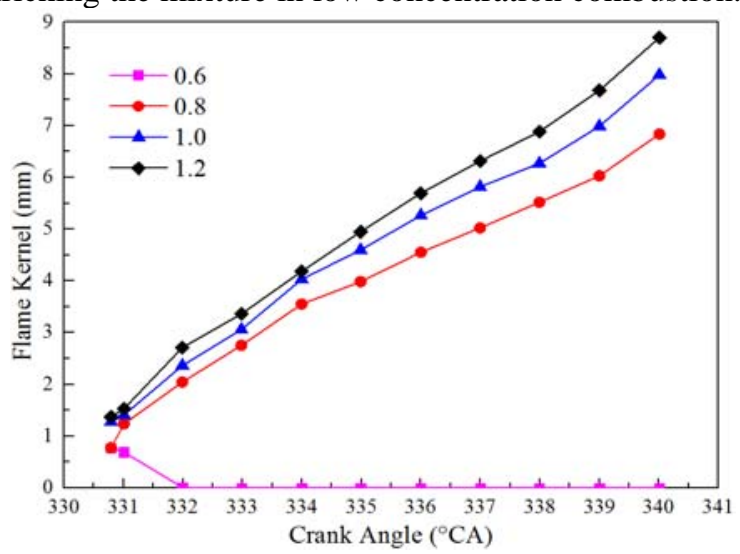

Figure 9. Flame kernel radius at different equivalence ratio

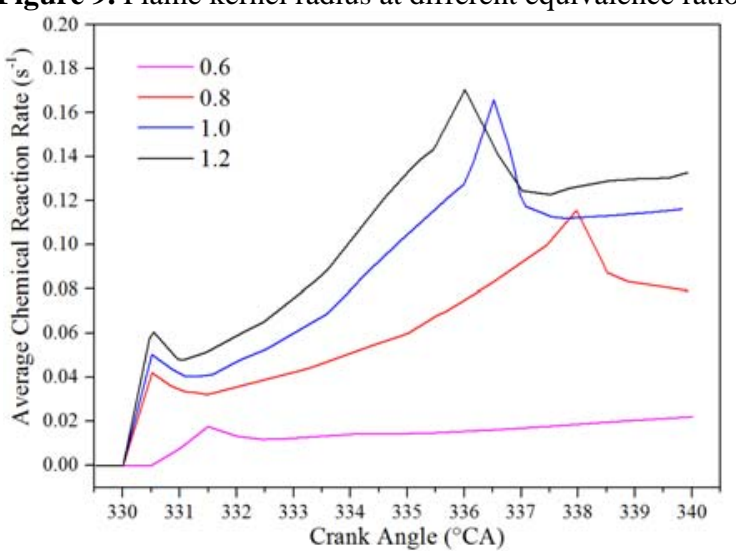

Figure 10. Chemical reaction rate at different equivalence ratio

\subsection{Influence of initial temperature on ignition}

It's difficult to ignite the low-heat-value biogas if the temperature in cylinder is low at ignition timing, so the initial temperature at ignition timing is one of significant influencing factors for the ignition performance. The initial temperature was changed from $400 \mathrm{~K}$ to $600 \mathrm{~K}$ and the combustion was separately simulated, the results were shown in Table 7, Figure 11 and Figure12.

Table 7 Results at different initial temperature

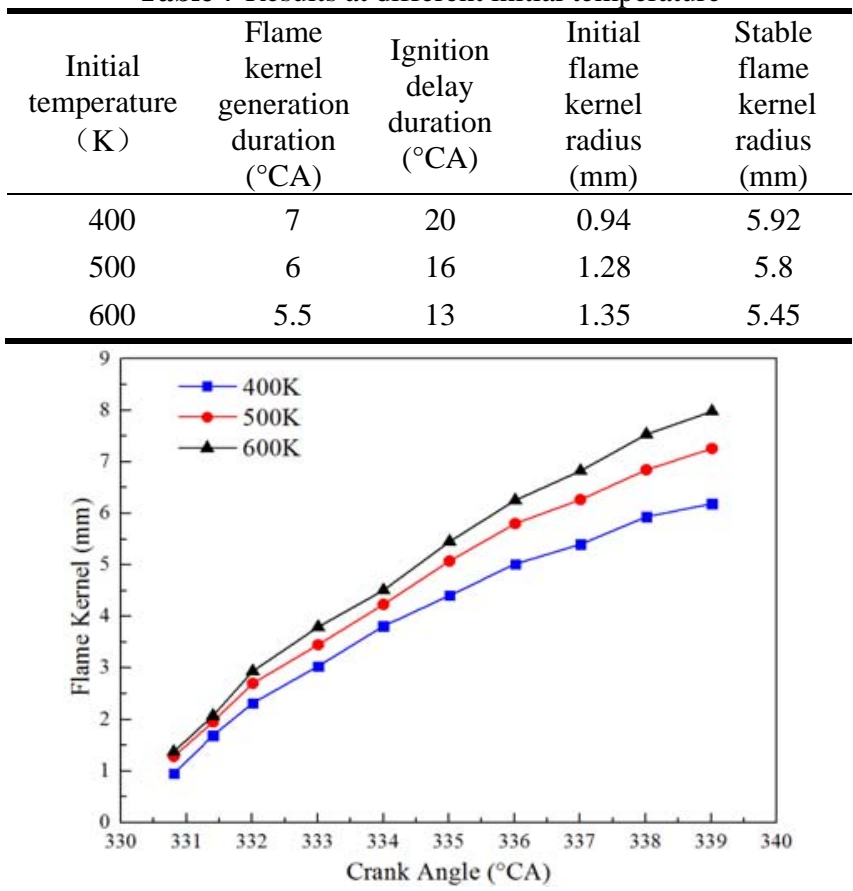

Figure 11. Flame kernel radius at different initial temperature

From Figure 11, the initial flame kernel radius and stable flame kernel radius decrease with the raise of the initial temperature. The raise of the initial temperature reduces the heat that transferred from the kernel to the unburned mixture, so the burned biogas mixture is reduced when the stable flame kernel is generated.

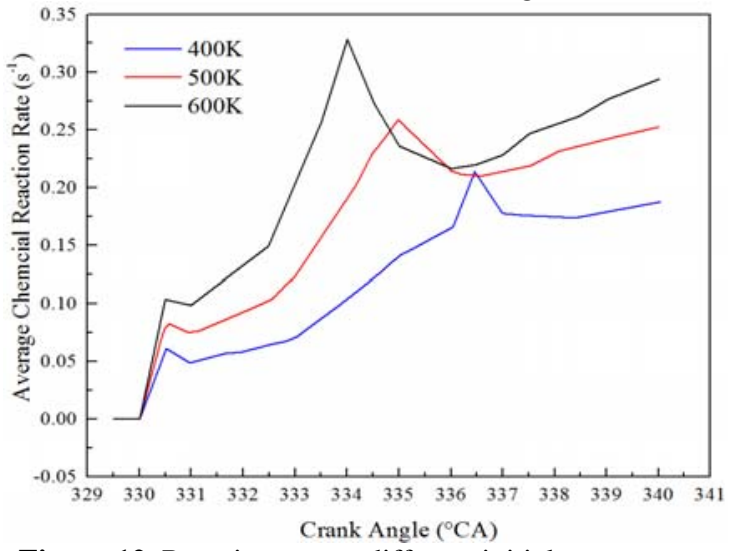

Figure 12. Reaction rate at different initial temperature

As shown in Figure 12, the average chemical reaction rate increases with the raise of the initial temperature. Therefore, the rate of flame developed is faster and the ignition delay duration is shorter. In a word, the raise of initial temperature reduces the ignition duration, which is beneficial to the ignition and combustion for biogas engine. 


\section{Conclusion}

(1) The ignition process of biogas engine can be described as three stages. The initial flame kernel generating stage, mainly influenced by spark discharge; the flame kernel developing stage, mainly influenced by combustion of biogas; the stable flame propagation stage.

(2) Once ignited successfully, the ignition energy has little effect on ignition process for biogas engine. Enlarging the spark plug gap in certain range is beneficial to the generation and development of the flame kernel and it will shorten the ignition delay duration. There is a minimum ignition energy and spark plug gap to ignite the biogas engine. Once below this level, the biogas engine cannot be ignited successfully.

(3) The equivalence ratio has obvious effect on the ignition performance by influenced the concentration of biogas mixture. Increasing the equivalence ratio in certain range will increase the combustion rate, reduce the initial flame kernel radius and shorten the ignition delay duration. It is beneficial to the generation and development of the flame kernel. Once beyond the range, increasing equivalence ratio is against to the generation and development of the flame kernel.

(4) The initial temperature has evident effect on the ignition performance by influenced the chemical reaction rate of the biogas. Preheating the biogas mixture will increase the combustion rate and shorten the flame kernel generation duration and ignition delay duration. It is beneficial to the generation and development of the flame kernel.

\section{Acknowledgements}

This work was financially supported by Supported Research Innovation Fund of Harbin Institute of Technology.

\section{References}

[1] Shi Shaoxi. Recent Progress in Combustion Technologies for Automotive Engines [J]. Journal of Combustion Science and Technology, 2001, 01:1-15.

[2] Zhang Liang, Huang Zhen. Life Cycle Assessment and the Selection of Natural Gas-based Vehicle Alternative Fuels [J]. Automotive Engineering, 2005, 05:50-53.

[3] Jing Heng, Chen Ligong, Zhu Haijun. Development of Substitutive Fuels for Internal Combustion Engines [J]. Energy Research and Information, 2005, 01:55-59.

[4] Rakopoulos CD, Scott MA, Kyritsis DC. Availability Analysis of Hydrogen/Natural Gas Blends Combustion in Internal Combustion Engines [J]. Energy, 2009(33):248-255.

[5] Sridhar G, Paul PJ, Mukunda HS. Zero-dimensional Modeling of a Producer Gas-based Reciprocating Engine [J]. Renewable Energy, 2007(26):155-162.

[6] Zhang Qiang. Numerical Simulation and Experimental Research on the Working Process of the Biogas Engine [D]. Shandong University, 2006:111-112.

[7] Xiong Shusheng, $\mathrm{Hu}$ Shugen. Fast Burning Combustion Study and Product Development for Biogas Engine [J]. Acta Energiae Solaris Sinica, 2002(41):477-481.

[8] Ji Zhouying. Biomass Gas Engine Performance Research in Distributed Energy [D]. Harbin Institute of Technology, 2013:18-42.

[9] Jiang Deming. Combustion and Emissions of the Internal Combustion Engine [M]. Xian Jiaotong University. 2001.07.

[10]Colin O, Benkenida A, Angelberger C. 3D Modeling of Mixing, Ignition and Combustion Phenomena in Highly Stratified Gasoline Engines [J]. Oil \& gas science and technology, 2003, 58(1): 47-62.

[11]Yang Zhenzhong, Wei Jianqin, Li Jingding. An Investigation of Optimum Control of Ignition Timing and Injection System in an In-cylinder Injection Type Hydrogen Fueled Engine[J]. International Journal of Hydrogen Energy, 2002, 27(2):90-93. 